\title{
OLINDA
}

\section{MEMÓRIA E ESQUECIMENTO}

\author{
VIRGÍNIA PONTUAL \\ VERA MILET
}

R E S U M O Este artigo discute as recentes práticas urbanisticas em sitios históricos, destacando aquelas exaltadas, por uns, como um novo e eficiente modo de pensar as cidades e criticadas, por outros, como "culturalismo de mercado". A essas criticas acrescenta-se outro argumento: o de que tais práticas usam a história do lugar como valor cultural, mas intervêm esvanecendo a sua especificidade e singularidade. Adotando a reconstituição histórica da formação do sítio de Olinda, responde à seguinte indagação: que práticas dos urbanistas levam ao esquecimento ou à memória da história do lugar? Assim, estão relatados fatos do passado que parecem denotar destruição e perda. No decorrer do artigo relaciona-se essa discussão aos relatos de memorialistas e textos de historiadores que informam sobre a formação da então vila da Capitania de Pernambuco.

P A L A V R A S - C H A V E História; urbanismo; práticas urbanisticas; organização urbanistica; memória; esquecimento.

\section{INTRODUÇÃO}

As recentes práticas urbanísticas relativas aos sítios históricos têm sido exaltadas como um novo e eficiente modo de pensar as cidades. Entretanto, vozes como as de Arantes (1998; 2000), Hall (1995) e Jeudy (1990) têm ecoado no sentido de pôr em dúvida tais práticas, enunciando que elas não passam de "culturalismo de mercado", "cenografia gestionária da cidade" ou "teatralização da vida social". As críticas ao new urbanism e à "terceira geração urbanística", vernáculos designativos das vertentes norte-americanas e européias, fundamentam-se no vazio de ideais que tais práticas contêm, nas quais a requalificação implica a minimização da ação do Estado na gestão do espaço público, na adoção de uma estratégia empresarial segundo os fluxos do mercado e na adoção de políticas de "marketing cultural".

De modo complementar a essas críticas, Harvey (1993; 1996), referindo-se às diversas experiências realizadas nas duas primeiras gerações, como em Baltimore e Londres, afirma que tais práticas resultaram numa "repetição em série de modelos bem-sucedidos (...) que deixaram a maioria das grandes cidades do mundo capitalista avançado com poucas opções além da competição entre si, em especial como centros financeiros, de consumo e de entretenimento" (1993, p.92). Quanto aos projetos urbanísticos da terceira geração, Arantes (2000) mostra terem-se tornado principalmente empreendimentos de valorização imobiliária, sob o comando e os ícones das grandes corporações internacionais, relegando práticas urbanísticas de controle do crescimento urbano para adotar aquelas de incentivo incondicional a esse crescimento.

Porém, não basta citar e referendar tais críticas, mas também enfatizar que as práticas "estratégicas" de "gerenciamento empresarial" ou de "marketing cultural" parecem ter

1 Segundo Arantes (2000), os projetos de renovação urbana podem ser ordenados segundo três gerações: a primeira, relativa aos anos 70, confere ênfase à parceria público-privado; a segunda, nos anos 80, critica os planos normativos e o planejamento quantitativo, passando a dar destaque à imagem urbana que tais empreendimentos proporcionam como uma dimensão qualitativa; e a terceira, relativa aos anos 90, é marcada pela emergência da dimensão cultural. Sobre esta temática ver ainda: Vicentini (2001) e Castello (2001). 
como pressuposto a diluição da cultura e da memória do lugar. Tais práticas estão entranhadas de incoerências, pois usam a história do lugar como valor cultural, mas intervêm homogeneizando de modo a se configurar um mesmo padrão de uso e de fruição da cidade e, portanto, esvanecendo a sua especificidade e singularidade.

Se, na atualidade, essas práticas urbanísticas provocam o esquecimento do passado à medida que são intervenções uniformizadoras de lugares, a reconstituição histórica pode trazer outros elementos às reflexôes sobre os atos dos urbanistas, considerando-se a seguinte indagação: Que práticas dos urbanistas levam ao esquecimento ou à memória da história do lugar?

O percurso a ser seguido para refletir sobre essa indagação procura desprender-se de uma postura romântica de fervor pelo passado, como também daquela adotada pelos renascentistas de um futuro superior decorrente do progresso da ciência. Portanto, a reflexão sobre as intervenções em sítios históricos nem poderia estar presa a um apego desmedido pelo antigo, nem à aceitação de novidades redentoras. Assim, pretende-se fazer uma reflexão circunscrita à relação ambígua entre memória e esquecimento.

O entendimento de memória, como ordenação dos vestígios ou trazer fatos do passado, deixa ao largo algumas lagunas. Para Le Goff (1996, p.424, 426, 472-3), memória é, ainda, rememorar ou dar idéia de, e conservar algo consciente ou latente, enquanto o esquecimento, para esse historiador, é perda, é amnésia. Porém, Benjamim (1985, p.45) associa esquecimento a envelhecimento, mas, ao estabelecer o entrecruzamento com reminiscência, afirma a constituição de "um mundo em estado de semelhança", que contém "força rejuvenescedora” ou revitalizadora. Nesse sentido, ao procurar conservar um sítio histórico não estariam os urbanistas realizando um ato de esquecimento, porém estabelecendo semelhanças entre maneiras de viver na cidade do passado, presente e futuro.

Para fazer essa reflexão, serão relatados fatos do passado que parecem denotar destruição, perda, esquecimento, a exemplo do incêndio de Olinda, realizado pelos holandeses, em 1631. Será que esse incêndio pode ser interpretado como um ato de esquecimento? É possível estabelecer um paralelo entre tal ato, num passado remoto, e os atuais atos de revitalização efetivados em sítios históricos?

No decorrer deste texto, buscar-se-á relacionar as questóes acima colocadas com relatos de memorialistas e textos de historiadores que informam sobre a formação da então

2 A capitania de Pernambuco foi uma das maiores do Brasil colonial, com uma extensão de costa de 60 léguas, que começava na foz do rio São Francisco e terminava no canal que separa a ilha de Itamaracá do continente. vila da Capitania de Pernambuco. ${ }^{2}$ Para tanto, foram selecionados os textos mais relevantes, ou que possuem maior força expressiva e documental.

\section{O INCÊNDIO DA VILA DE OLINDA: QUESTÃO MILITAR E IDENTIDADE DO LUGAR}

O principio do mez de novembro foi gasto completamente em remover tudo da cidade de Olinda e arrazal-a (...) Quando retiraram da cidade de Olinda tudo quanto podia servir e ser transportado e removeram a bagagem dos officiaes e dos soldados, o tenente-coronel ordenou que as tropas se apromptassem para mudar de acampamento. No dia 24 de novembro, pela manhã, o chefe da equipagem foi do Recife para a cidade, com archotes alcotroados e outros meios incendiarios e mandou atear fogo ás casas, sendo tudo devorado pelas chamas (...) (Laet, 1916, p.296-7.)

Esta descrição de Joannes de Laet, historiador holandês dos feitos praticados no Brasil até o ano de 1636, mostra que o incêndio não foi um impulso no decurso de uma 
batalha, mas algo perseguido e desejado. As justificativas para tal façanha estão registradas por vários memorialistas holandeses e portugueses, assim como em estudos recentes de historiadores pernambucanos.

Dos registros coletados, o mais prenhe de significação é o de Gaspar Barlaeus. Esse professor holandês, apesar de nunca ter estado no Brasil, registrou os feitos da Companhia das Índias Ocidentais no Brasil, principalmente aqueles empreendidos sob o governo do Conde João Maurício de Nassau, a quem ele chamou de "ex-governador supremo do Brasil holandês":

Desde que começaram, porém, a senhorear o Brasil os holandeses, subjugadores das terras e das águas, aprouve escolher-se o Recife e a Ilha de Antônio Vaz para sede do governo. Como que condenada pelo destino, arruinou-se a formosa Olinda, mostrando-se chorosa. As casas, os conventos e as igrejas, derribados, não pelo furor da guerra, mas de propósito, lagrimavam com a própria ruina. (Barlaeus, 1980, p.154.)

Sugere este memorialista que, mesmo antes da invasão, os holandeses já rejeitavam Olinda. Entretanto, outros memorialistas não são tão enfáticos nesse ponto. Pelo contrário indicam ter sido tentado, inicialmente, dominar e ocupar essa cidade. Porém, após a realização de estudos, concluíram que a melhoria de sua segurança exigia um complexo sistema de fortificações, cujos custos eram elevados, justificando-se, assim, a decisão de sua destruição:

Nesse interim, como viessem ordens da Metropole determinando ao Governador e ao Conselho que conservassem a cidade e não a abandonassem, custasse o que custasse, elles resolveram mandar examinar com maior escrupulo, por todos os engenheiros, constructores e officiaes entendidos em fortificaçôes, a situação da mesma. Sahindo da cidade, mediram muito rigorosamente toda a circunferencia, observando todas as circunstancias e juntamente a planta do que devia fortificar, tomando notas sobre as condiçóes do terreno e dos logares vantajosos ou não; e, finalmente, considerando o numero de tropas, o tempo, as despesas e outras exigencias necessarias para uma tal fortificação, opinaram por unanimidade que sahiria ella excessivamente cara á Companhia e que seria de difficil conservação (...) O Conselho de Guerra, sendo consultado sobre a presente situação (...) foi de parecer que se devia manter a cidade de Olinda o mais tempo possível, em todo o caso até chegar ordem da metropole (...) o Conselho e o Governador estiveram occupados quasi todo o mez discutindo se deviam ou não evacuar a cidade de Olinda; e, como a maioria fosse pelo seu abandono, começaram a transportar todos os materiais aproveitaveis para o Recife. (Laet, 1916, p.283-4, 296.)

Joannes de Laet relatou estes fatos bem anteriormente a Barlaeus. É provável que este último, ao querer enaltecer os feitos de Nassau, tenha minimizado a importância de Olinda e a resistência do Conselho dos XIX em destruí-la. O historiador pernambucano José Antônio Gonsalves de Mello, a partir das cartas trocadas entre o Conselho dos XIX, o Conselho Político de Pernambuco e o então governador, coronel Diderich van Waerdenburch, reforça as memórias de Joannes de Laet:

Waerdenburg, os seus subordinados e os engenheiros que serviam na tropa foram unânimes em reconhecer a grande dificuldade de manter, sem perigo para a segurança da 
O L I N D A, M E M Ó R I A E E S Q U E C I M E

conquista recente, a cidade de Olinda (...) Na Holanda, porém a sugestão para abandonar Olinda não encontrou boa acolhida (...) Apesar disto, em Pernambuco, os holandeses resolveram não fortificar Olinda, o que já era uma razão para abandoná-la (...) Waerdenburg urgia, em carta ao Conselho dos XIX, por uma decisão: a situação militar agravara-se com o desembarque de 1000 homens da frota de D. Antônio de Oquendo (...) em 24 de novembro de 1631 evacuou a cidade de Olinda e em seguida incendiou-a (...) Esta, a história de Olinda - uma espécie de vida, paixão e morte - sob a dominação holandesa. (Mello, 1987, p.45-8, 70.)

No tocante aos aspectos defensivos e à fragilidade da vila de Olinda, não se pode deixar de fazer referência às discussões levantadas pelos portugueses. Conforme o historiador Evaldo Cabral de Mello, em relatos de Diogo de Campos Moreno escritos nos primeiros anos do século XVII, está indicado que essa vila não poderia ser adequadamente fortificada, e, portanto, estaria sempre exposta aos agravos das guerras e invasões:

A vila de Olinda em nenhum tempo pode ter fortificaçóes que assegure suas coisas por ser, como se vê, em assento alto e barrancoso, as casas esparcidas e as ruas de modo desencaminhadas que uma de per si faz um bairro, e as igrejas distantes e desacompanhadas, de modo que as trincheiras da praia, que é a maior fortificação em que se estriba, não é de nenhum efeito, para caso repentino de gente resoluta, quanto mais para um caso pensado, no qual ainda os altos muros e largas cavas não asseguram totalmente um povo bisonho. A melhor defesa de Olinda, pensava Diogo de Campos, consistia no Recife, que pode ser muito grande e muito forte por razão do assento no salgado, cercado de água. (Mello, 1995, p.146.)

3 Segundo Mello (1987, p.45), nos documentos dos holandeses dos primeiros anos Olinda era denominada como cidade.
Segundo esse historiador, Diogo de Campos Moreno teria chegado a prever que uma força naval inimiga não encontraria dificuldade em desembarcar uma tropa na barra de Pau Amarelo, ao norte da vila, a qual, marchando pela praia, tomaria facilmente Olinda. Exatamente o cenário que seguirão os batavos em 1630.

O pequeno poder defensivo da cidade de Olinda ${ }^{3}$ é a razão mais fortemente evocada para justificar ser esta incendiada, porém as memórias escritas por Barlaeus indicam razões que a própria razão desconhecia:

Não parecia sacrilégio aos nossos essa demolição (...) convencidos de que todo o lugar é igualmente sagrado e idôneo para se adorar a Deus, julgavam que não cometiam nenhuma impiedade, mas praticavam um ato de inteligência, desejando dar maior segurança à nova cidade e ao seu culto (...) Sendo nós, porém, homens e capazes de comover-nos com o belo, não podiam deixar de lamentar a assolação da cidade aflita aqueles mesmos que a devastavam, pondo por terra o tôpo das igrejas e dos edifícios públicos e privados (...) E se a gente agora visse Olinda, juraria que contemplava, jazendo em seu local desolado, Pérgamo, as ruínas de Cartago ou de Persépolis (...) desaparecendo a mãe - Olinda - lhe sobrevivesse das ruínas, embora com outro aspecto, a sua filha - Mauriciópole. (Barlaeus, 1980, p.154.)

Esse fragmento das memórias de Barlaeus tem força e significação, apesar da ironia contida, por colocar a questão religiosa associada à militar, ou seja, as cortes européias eram, também, comandadas pelas Igrejas católica e protestante, que professavam, cada uma, diferentes visões de mundo, expressas, inclusive, na organização das cidades de então. 
O componente religioso na formação urbanística e cultural dos primeiros tempos de Olinda pode, também, ser ilustrado com as memórias de Frei Manuel Calado. Ao iniciar seus escritos, ele faz uma comparação entre o pecado e as desgraças acometidas aos delinqüentes ou pecadores, enfatizando ser o pecado a causa e o efeito da perversão e destruição das coisas. Essa comparação é feita para explicar a invasão dos holandeses à capitania de Pernambuco como castigo divino decorrente dos desmandos aí então presentes:

Quem se houvesse achado na vila de Olinda (...) antes que os holandeses a ocupassem, e a tornasse a ver depois que nela entraram os holandeses, e a renderam, sem muito parafusar, em breve alcançaria, que havia sobre ela caído a vara da divina justiça; a instância dos pecados em que estava enlodada. $\mathrm{O}$ ouro, e a prata era sem número, e quase não se estimava; o açúcar tanto que não havia embarcações para o carregar (...) As delícias de mantimentos e licores, eram todos os que se produziam assim no reino, como nas ilhas. $\mathrm{O}$ fausto, e aparato das casas era excessivo, porque por mui pobre, e miserável se tinha o que não tinha seu serviço de prata (...) As mulheres andavam tão loucãs, e tão custosas, que não se contentavam com os tafetás, chamalotes, veludos (...) e eram tantas as jóias com que se adornavam (...) Os homens não haviam adereços custosos de espadas, e adagas, nem vestidos de novas invenções, com que não se não ornassem os banquetes quotidianos (...) Entrou nela o pecado, foram-se os moradores dela, entre a muita abundância, esquecendo-se de Deus; e deram entrada aos vícios, e sucedeu-lhes (...) e às mais cidades circunvizinhas, que foram abrasadas com fogo do céu. (Calado, 1985, p.38-9.)

A abundância e a riqueza estavam presentes não apenas nos hábitos dos seus moradores mas, principalmente, nos edifícios religiosos pertencentes às congregaçōes da Igreja católica. O poder de mando dessas congregaçóes pode ser avaliado pela ocupação do topo das colinas por edificações religiosas, isto é, as melhores localizações em termos de visibilidade e domínio do ambiente eram de propriedade religiosa.

Historiadores de nosso tempo têm discutido a relação entre território e estratégia locacional, para fazerem vingar posiçóes de mando e superioridade, destacando a arquitetura jesuítica como uma das que mais utilizaram esse recurso:

(...) vê-se ao longe a igreja e o Colégio como agentes do núcleo urbano, como representantes legítimos deste. Estão no alto, soberanos - uma simbologia de posição e hierarquia - o poder simbólico da altura concretiza-se na implantação dos seus edifícios. A paisagem ao redor faz-nos perceber sua imponência e lhe rende homenagem, tributa-lhe respeito. A altura sacraliza o monumento, confere-lhe poder pela proximidade do céu, pela largueza da visão. (Oliveira, 1988, p.35-6.)

Vale conferir, nas gravuras da época (Figuras 1, 2, 3), a localização das edificações religiosas, principalmente a do Real Colégio dos jesuítas, cuja implantação na cota mais alta da colina predominava sobre as demais construçóes.

A gravura Marin D'Olinda de Pernambuco, presumidamente de um anônimo, ilustra as memórias do historiador holandês Johannes de Laet (1916), realizadas em 1630, mostrando uma paisagem idílica, paradisíaca, e de igual modo estranha, onde o mar, o céu e as colinas absorvem em grande medida a cena, mas o foco central são as marcas do homem português. Este último, ao ocupar o território, escolheu os locais de maior visibilidade para marcar a sua presença. Embora a composição dos elementos construídos guarde nessa 
gravura equilíbrio na disposição das edificações, o mesmo não se pode dizer quanto ao caráter estamental, pois em grande maioria são elas religiosas. Dessas edificações, a de maior destaque é a Matriz do Salvador (A), complementada pelos conventos dos jesuítas (B), franciscanos (C), São Bento (E) e Carmo (R), e por uma outra matriz, a de São Pedro (L). Assim, as edificações religiosas, sob o olhar de um artista, mostram uma organização de cidade diversa das holandesas e evocam semelhanças com a atual Olinda.

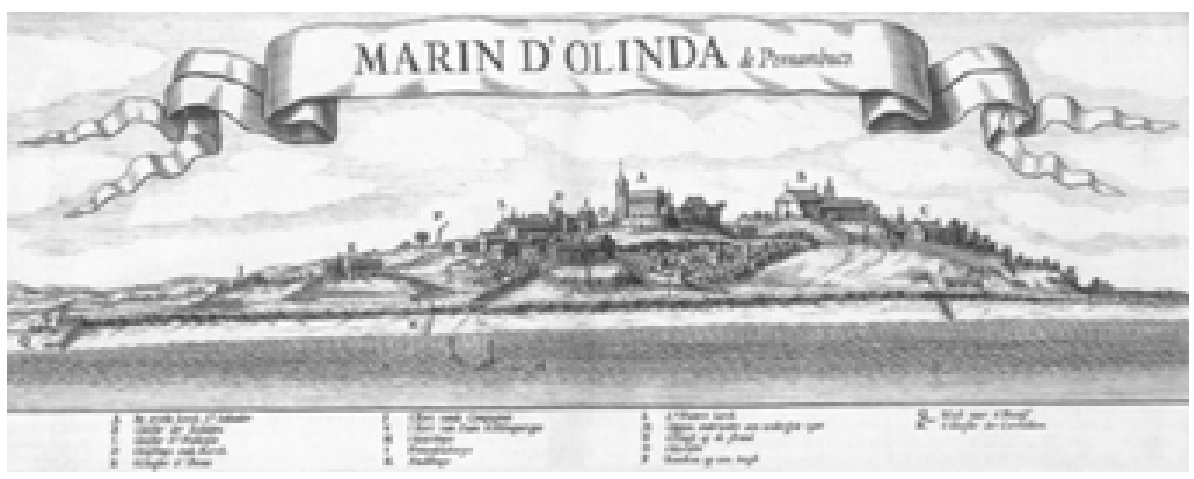

Figura 1 - Marin D’Olinda de Pernambuco.

A vista panorâmica de Olinda (Figura 2), gravada por Claes Jansz Visscher (1630), é parte da descrição da invasão de Pernambuco. Essa gravura, desenhada numa perspectiva mais distante do que a anterior e acima da linha de horizonte, destaca entre as edificações o convento dos jesuítas. Esse outro olhar expõe, também, extensas superfícies de água, terra e firmamento, mas é muito parcimonioso quanto à vegetação. Talvez o autor não quisesse diluir os elementos relativos à ocupação pelo homem. A representação da cena, do lugar do desejo e da astúcia do invasor pode ser superposta a outras fisionomias do passado e do presente, possibilitando a figuração de diversas Olindas, todas elas belas e majestosas, assim como recoloca, para quem as visualiza, o desejo de posse e permanência do lugar.

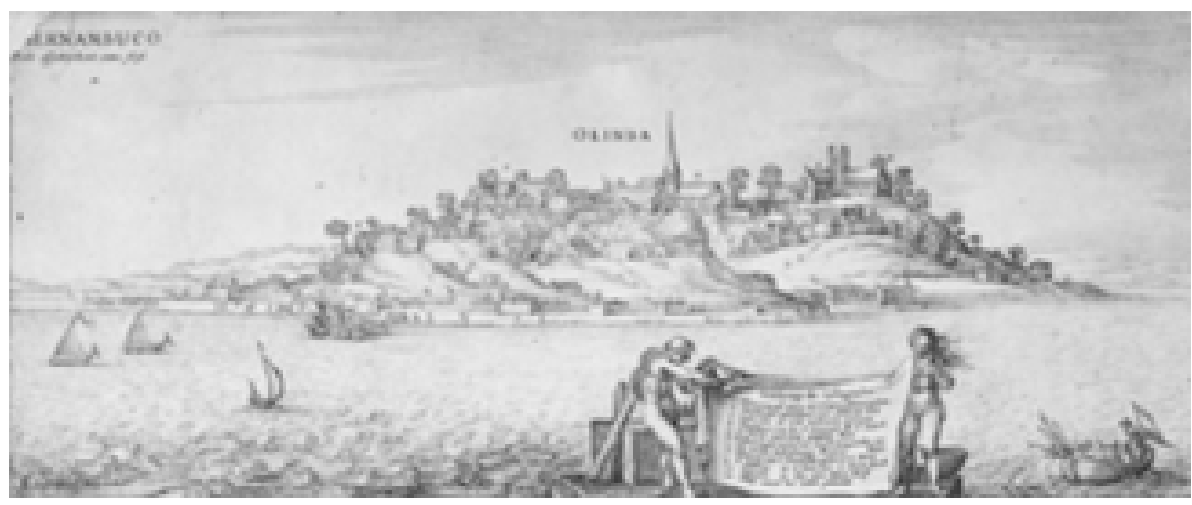

Figura 2 - Olinda, por Claes Jansz Visscher (1630).

A paisagem de Olinda (Figura 3), gravada pelo pintor holandês Frans Post e constante do livro de Barlaeus (1980), retrata, a partir de ângulo tomado da praia, a vila depois do incêndio, mostrando as ruínas e edificações que se mantiveram, como o convento dos jesuítas, do Carmo e a Matriz do Salvador. Esse quadro, desenhado após a volta de Post à Holanda, como outros, embora representem paisagens brasileiras "não deixam 
de ser holandesas (...) nas quais o céu no Brasil toma o lugar da água na Holanda” (Oramas, 1999, p.220). Essa interpretação dos quadros de Post por Oramas tematiza a reinvenção da paisagem como um ato de recordação e memorização, isto é, ao desenhar Post a maioria de seus quadros na Holanda, as paisagens reproduzidas a partir de recordaçóes de um lugar distante significam, também, perda ou esquecimento (1999, p.224).

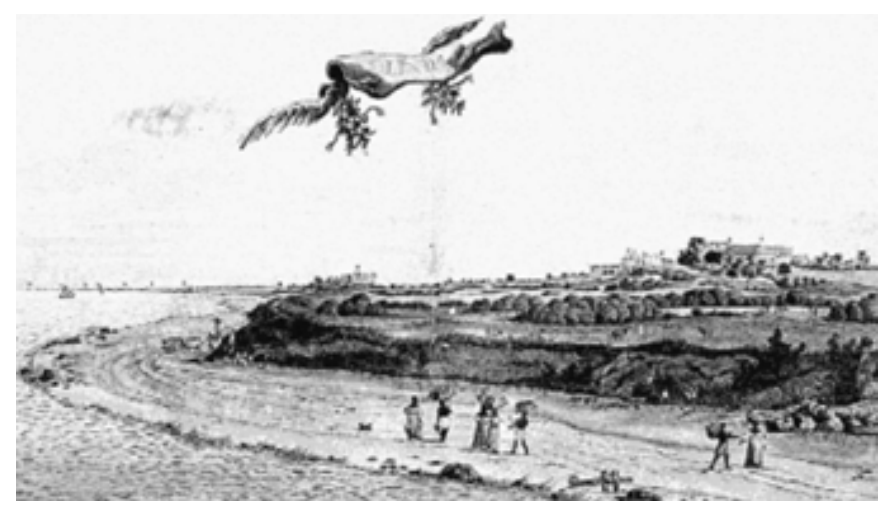

Figura 3 - Olinda depois do incêndio (Frans Post).

Tais gravuras de artistas holandeses retratam Olinda bela e majestosa. Após o incêndio, já não dava para mostrá-la de igual maneira, mas dava para afirmar, ainda, a preponderância do componente religioso na organização urbanística da vila.

Dessa forma, se por um lado a beleza de Olinda era reconhecida e exaltada também pelos holandeses, por outro, era esvanecida pela inexistência de elementos arquitetônicos relativos ao protestantismo. Portanto, pode-se pensar que o ato de incendiar Olinda, mais do que previsto e "proposital", mais do que ter sido considerado como um "ato de inteligência”, era desejado. A vila de Olinda era coisa a ser extinta, perdida, enfim, esquecida. Esse desejo está aludido no paralelismo estabelecido com atos ocorridos na Antigüidade grega e romana, mas o mais significativo é o realizado por meio da relação "mãe e filha", deslocando fantasias e sentimentos, ou seja, palavras que dizem de desejos insatisfeitos, situados preponderantemente no domínio da subjetividade e não apenas da objetividade dos interesses materiais. Esse ato de esquecimento, entretanto, propiciou em si próprio a recordação de uma arquitetura florescente e bela, assim o movimento pela reconstrução de Olinda foi um trazer de volta um modo de habitar, de conservar de forma consciente a memória dos portugueses e brasileiros, como disse José Antônio Gonsalves de Mello: "Um modo de demonstrar reação ao invasor, de não conformidade e antagonismo às suas idéias” (Mello, 1987, p.58).

\section{A ORGANIZAÇÃO URBANÍSTICA DE OLINDA: 1530 - 1631, DOS PRIMÓRDIOS DA OCUPAÇÃO AO INCÊNDIO}

A beleza de Olinda foi sempre referida desde seu donatário Duarte Coelho, passando pelos demais funcionários portugueses e viajantes de outras nacionalidades. Já nos seus primórdios, os aspectos paisagísticos encontram-se largamente documentados. Cunhada de "formosa" pela beleza natural que propiciava do alto de suas colinas, a vila passou a ser complementada com as diversas construçóes empreendidas pelo homem, 
mais precisamente pelos representantes do Rei e da Igreja católica de Portugal. Foi essa dimensão paisagística que, segundo os rumores da história, motivou o donatário a escolher o sítio para sede da sua capitania ao exclamar: "Oh! Linda terra e outeiro para edificar uma villa!" (Mello, 1974, p.19).

Discorrendo sobre o encantamento que Olinda provocava nos visitantes, o historiador José Antônio Gonsalves de Mello evoca Manuel de Figueiredo, autor de um roteiro de navegação que, em 1614, descreveu a paisagem da perspectiva dos que chegavam de barco:

A vila no alto dos seus morros, se apresentava espinhosa por cima e são os coqueiros e a torre que está no meio dela e algumas casas grande que se fizeram pelo alto da povoação (...) a terra baixa é toda igual cheia de arvoredo muito espesso. (Mello, 1983, p.37.)

Essa recorrência à dimensão paisagística permanecerá como depoimento unânime de pintores e gravadores, como também de todos aqueles que versam sobre Olinda, ao longo de quase cinco séculos.

Tais depoimentos, sejam em forma de pinturas, gravuras, desenhos, seja por meio de textos escritos, constituem não apenas vestígios do passado mas a afirmação de uma rememoração consciente que estabelece semelhanças. De igual modo, ao reconstituir os primórdios da organização urbanística de Olinda, pretende-se evocar fatos, fazer reminiscência. Apesar de a presente reconstituição ser parcial, em largas pinceladas, ela memoriza com o olhar do presente um outro tempo, realizando deslocamentos na vivência de uma cidade.

Quanto à dimensão urbanística, os princípios que orientaram a ocupação territorial

40 Foral de Olinda foi redigido em 1537 por Duarte Coelho, donatário da capitania de Pernambuco. Constitui documento de inestimável valor histórico, pois, por meio dele, tornou-se possível realizar a reconstituição dos primórdios do processo de ocupação territorial de Olinda, sede da Capitania de Pernambuco. Deve-se o resgate dos textos do Foral a José Antônio Gonsalves de Mello que, a partir da confrontação de sete cópias manuscritas existentes em diversos arquivos, elaborou sua reconstituição textual, dividindo o texto em parágrafos numerados para maior facilidade do leitor (Mello, 1974, p.37-57). podem ser apreendidos mediante a leitura e interpretação do texto do Foral de Olinda ${ }^{4}$ carta de doação que faz o donatário ao Concelho da vila de Olinda, que, no dizer de Oliveira, constitui a "certidão de nascimento da vila de Olinda, capital da capitania de Pernambuco" (Oliveira, 1996, p.2). Essa carta registra os direitos sobre foro da Câmara de Olinda, delimita os traços gerais da ocupação do território, a toponímia dos arruamentos e demais lugares, já existentes à época da doação, e mais, define diretrizes de natureza ambiental, relativas aos cuidados com a utilização dos matos das praias e mananciais de água potável, ou seja, o Foral informa sobre a concepção do donatário no que tange ao ordenamento e usos do solo, constituindo-se num verdadeiro plano de ocupação territorial. Discutindo a ocupação territorial da capitania e o início do núcleo urbano de Olinda, Oliveira salienta:

Segundo os mais conceituados historiadores em 9 de março de 1535, Duarte Coelho desembarca no limite norte da sua capitania, local da antiga feitoria régia, no porto que os índios chamavam de Pernambuco. Logo resolveu procurar um local mais seguro e vantajoso para estabelecer a sede do seu governo. Rumou uma légua para o sul, chegou a um outeiro junto ao mar, na confluência dos rios Capibaribe e Beberibe, com um bom porto a pequena distância, uma várzea extensa, ideal para a agricultura, os arvoredos eram densos e nas áreas mais baixas, onde as marés inundavam na preamar, próximo a foz dos rios apareciam os mangues onde existiam vários tipos de crustáceos e uma grande variedade de peixes. Nas praias arenosas abundavam árvores frutíferas, predominantemente o caju (...) Para se proteger dos freqüentes ataques dos índios, o pequeno povoado se desenvolveu sobre as colinas e confinado entre paliçadas, tendo como estratégia, um esquema defensivo elementar, 
caracterizado pela altura do sítio, que permitia o controle, à distância das vias de comunicação e o recuo da área povoada em relação ao mar. (Oliveira, 1996, p.2.)

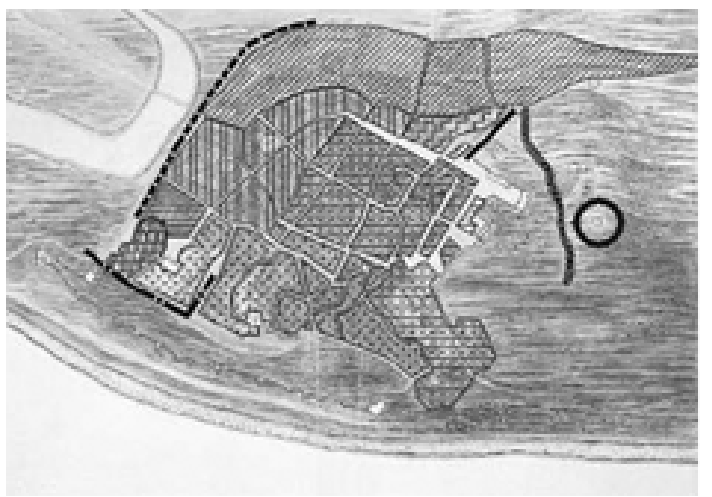

Figura 4 - Ocupação territorial. Desenho elaborado sobre o mapa de Golijath (1948).

O Foral ou plano de ocupação territorial transposto para outra linguagem, a do desenho (Figura 4), materializa uma intenção, uma concepção de domínio e conquista das terras e dos gentios. O desenho, ${ }^{5}$ elaborado sobre o mapa de Golijath (1948), faz a correspondência entre as descrições dos caminhos e terras doadas ao Concelho de Olinda pelo donatário Duarte Coelho e a cartografia produzida sob o domínio holandês, ${ }^{6}$ mostrando a localização dos usos de então:

- Habitação - os assentos do monte e faldas dele, para casarias e vivendas para moradores e povoadores.

- Comércio - o porto dos navios, o varadouro e a lombada do monte para o estabelecimento das feitorias (casa da fazenda e alfândega e armazéns).

- Abastecimento alimentar - as roças de Braz Pires, Rodrigo Álvares, Paio Correia, D. Brites e Jerônimo de Albuquerque.

- Áreas de uso comum - o rossio, as várzeas das vacas, a de Beberibe e as que vão pelo caminho que vai para o paço do governador, o mato da praia, desde o varadouro até o rio Doce, os mangues, todas as fontes e ribeiras, e todos os varadouros, dentro do termo da vila.

Além do ordenamento territorial, o texto do Foral informa também sobre a existência de normas relativas ao meio ambiente: o "mato da praia", desde o varadouro até o rio Doce, era destinado à exploração restrita de lenha e reservado para serventia da vila e povo. Os mangues, áreas não agriculturáveis, destinados à exploração de "alimentos e criação de viveiros para comercialização local”. Todas as fontes e ribeiras, assim como os varadouros, eram destinados "ao serviço da Vila e povo dela que deveriam mantê-los, alimpar e correger à sua custa” (Oliveira, 1996).

Entre 1535 e 1537, a crer no que está descrito no Foral, já estavam estabelecidos os principais elementos definidores do traçado e composição urbana: o paço do governador, o Conselho, o rossio, a feitoria do governador, o porto, os caminhos que articulavam o paço do governador ao rossio e ao porto do Varadouro, e o caminho que saia do Varadouro para a várzea do Beberibe.

O historiador José Luís Mota Menezes pontua como a composição urbana foi sendo construída a partir da torre de pedra e cal e, defronte dela, foi construída a igreja matriz do Salvador e, posteriormente, a Casa de Câmara, formando a praça da vila:
5 Os dados apresentados foram pesquisados no Projeto Foral de Olinda, coordenado pela arquiteta e pes quisadora Valéria Maria Agra Oliveira, que gentilmente nos assegurou acesso à pesquisa por ela desenvolvida. Essa pesquisa reconstitui, por meio da cartografia e de documentos históricos, as bases territoriais da vila de Olinda. O Projeto Foral visa sobretudo, entre outros objetivos, reconstituir o direito da Prefeitura de Olinda sobre o patrimônio público das terras foreiras doadas por Duarte Coelho à vila de Olinda, em 1537.

6 Segundo o historiador Gonsalves de Mello (1976, p.28), Cornelis Sebastiaanszoon Golijath nasceu em Schiedam, entre 1610 e 1620 , e, no começo da década de 1640 , serviu como cartógrafo do Conde Maurício de Nassau no Brasil. Esse mapa de Golijath é considerado, por aquele historiador, como o melhor mapa das três cidades no Brasil: "Olinda de Pernambuco, Cidade Maurícia e Recife". 
(...) o donatário assenta as primeiras casas no alto da colina, onde se encontra a sua torre forte e onde próximo a esta constrói a matriz, além da Igreja e Hospital da Santa Casa de Misericórdia, estas situadas no outro extremo da rua principal. Naturalmente, estabelecida a administração, foram construídas a Casa da Câmara, a Cadeia, além do Açougue e Ferraria (...) Observa-se que as ruas seguem uma disposição que tem como referência inicial aquela colina antes citada. A ela se tinha acesso através de três ladeiras, a da Misericórdia, a da Matriz e uma terceira que ia em direção ao Rossio e ao salgado. (Menezes, 1998, p.338-341.)

No tocante ao arranjo urbanístico, a torre de pedra e cal e o Foral são as expressões primeiras da ocupação da capitania de Pernambuco pelo donatário Duarte Coelho. A torre, construção perpendicular ao solo, firmando um descolamento necessário para dominá-lo e moldá-lo ao gosto da formação das cidades nos territórios conquistados por Portugal, é referenciada em todos os depoimentos do primeiro século como elemento central, articulador da malha urbana. Essa construção, ao lado das igrejas e conventos, destacavase em meio às colinas, como expressão do poder de mando da capitania.

Gabriel Soares de Souza fala da fortificação construída no alto da colina, em forma de torre e em pedra e cal, como a primeira edificação que firmava a ocupação do que viria a ser a vila de Olinda:

Chegando Duarte Coelho a este porto desembarcou n'elle e fortificou-se, onde agora está a villa em um alto livre de padrastos, da melhor maneira que foi possível, onde fez uma torre de pedra e cal, que ainda agora está na praça da villa, onde muitos annos teve grandes trabalhos de guerra com o gentio e francezes (...) Esta villa de Olinda terá setecentos visinhos pouco mais ou menos, mas tem muitos mais no seu termo, porque em cada um d'estes engenhos vivem vinte e trinta visinhos, fóra os que vivem nas roças, affastados delles, que é muita gente (...). (Souza, 1938, p.27-9.)

Informa ainda Souza a população existente no ano de 1587 , não só no reduto da vila como também nos engenhos e roças, considerando ser esse contigente potencialmente soldados prontos a defender a capitania de Pernambuco. Portanto, ao lado das primeiras expressões urbanas, vale ressaltar que o mundo rural possuía uma dinâmica própria e importante na organização econômica, social e militar da capitania.

A essa população correspondia uma organização social composta pelos proprietários da capitania, compreendendo a família de Duarte Coelho, pelos clérigos, jesuítas (1551), carmelitas (1580), franciscanos (1585), beneditinos (1592), entre outros. Além dos militares, incluindo os engenheiros militares, personagens importantes nessas expedições, outros funcionários da coroa participavam também dessa população, sobretudo portugueses, vindos na comitiva do donatário. Muitos receberam terras por doaçôes e tornaram-se senhores de engenho, enquanto outros se tornaram negociantes. Aos lusitanos somaram-se os escravos negros e os índios. Segundo a filiação religiosa, essa população dividia-se em cristãos e cristãos-novos, muitos dos quais praticavam a religião judaica clandestinamente.

A localização do porto da vila de Olinda era apontada como um obstáculo a seu funcionamento desde o início da colonização. Mello (1974, p.51) salienta que, já em 1537, era intenção de Duarte Coelho abrir o rio Beberibe de forma a que fosse possível os navios terem acesso direto do oceano na área próxima ao Varadouro da galeota. Tal intenção pode ser identificada por meio do registro contido no Foral de Olinda: 
E porque por detrás do dito montinho, onde há de fazer o Senhor Governador a sua feitoria, há de se abrir o rio Beberibe e lançar ao mar por entre duas pontas de pedras, como tem assentado o Senhor Governador; entre o dito rio lançado novamente e as roças da banda de riba de Paio Correia e da Senhora Dona Brites e o mato que está adiante, que ora é do senhor Jerônimo de Albuquerque, há de ir uma rua de serventia ao longo do dito rio novo para serventia do povo, de que se possa servir de carros, que será de cinco ou seis braças de largo e rodeará pelo pé do montinho até o varadouro da galeota. (Mello, 1974, p.51.)

Visava o donatário, muito provavelmente, recolocar o modelo urbanístico reinol e estabelecer unidade espacial entre a cidade alta e a cidade baixa, no que demonstrou sensibilidade para as questôes de estratégia locacional. Tanto é que, no local indicado para implantação da sua feitoria ou em suas proximidades, localizou o donatário a Alfândega Real. Tal localização visava estabelecer o controle fiscal do transporte de mercadorias que saíam do varadouro, por meio de barcas, e seguiam até o porto da Ribeira do Mar, localizado no extremo sul da vila. Mais ainda: cuidou o governador de dotar o Varadouro de infra-estrutura viária, ao conceber a construção de uma via de serventia para o povo.

Documentos do final de século XVI comprovam a existência de caminho de carro de cinco ou seis braças de largura (cerca de 10 ou 12 metros de largura), que passa ao longo do montinho (isto é, nas proximidades do sopé da pequena colina em que, em 1596, foi erguido o mosteiro de São Bento) e segue até as margens do rio Beberibe (Mello, 1974, p.52).

Nestor Goulart (1968, p.126-7) supõe que no primeiro século as escolhas de sítio se fizeram, algumas vezes, de maneira aleatória, dada a superficialidade de conhecimentos sobre a terra. Em decorrência da inadequação da ocupação desses sítios ao crescimento que haveria de ocorrer posteriormente, diversas povoações desapareceram ou foram transferidas.

O fato é que, no caso de Olinda, as condições topográficas do sítio em que se instalou a sede administrativa da capitania, embora dentro dos melhores padróes de defesa pela altura, limitaram seu processo de ocupação e expansão territorial. De fato, as precárias condiçóes do porto de Olinda levaram ao ulterior desenvolvimento do Povo, ou seja, do assentamento urbano localizado na Ribeira do Mar, cujas facilidades locacionais - porto e acessibilidade aos engenhos por meio dos rios Capibaribe e Beberibe - favoreceram a sua consolidação.

A dependência urbanística entre a vila de Olinda e o porto dos Arrecifes dos Navios foi ungida desde os primórdios da ocupação portuguesa. Tal ligação estabeleceu uma especialização funcional, na qual a vila era o lugar das autoridades, da açucarocracia e do clero, e o porto, o local onde prosperavam as atividades portuárias, o comércio e o artesanato.

Os historiadores José Luíz Mota Menezes (s.d.) e Denis Bernardes (1987), ao discorrerem sobre essa dependência, associam-na a outros fatos, complementando a argumentação. O primeiro, ao tematizar a formação da vila de Olinda e do porto do Recife, indica não só a existência permanente dessa condição de dependência mas também salienta uma possível matriz urbana de origem luso-brasileira decorrente dessa condição. O segundo vincula tal dependência a fatos econômicos relativos à reprodução e ampliação de parte da economia colonial.

O quadro urbanístico da vila de Olinda estava assim delineado na ocasião da chegada dos holandeses, em 1630: 
O L I N D A, M E M Ó R I A E E S Q U E C I M E

No que diz respeito á praça de Olinda, temos a referir que ella está situada em forma de angulo no dorso de um alto monte, do qual uma extremidade é mais elevada do que a outra. No extremo mais alto do monte acha-se o Convento dos Jesuítas, sendo o extremo norte do lugar formado pelas encostas do mesmo monte; para o lado sul encontra-se o Convento dos Franciscanos, que tem um bonito pateo com uma bella fonte onde o povo vae buscar agua para beber. Descendo o monte, a partir do convento dos jesuítas, depara-se novamente com uma eminencia sobre a qual eleva-se a principal egreja parochial do lugar, chamada Salvador, a casa da camara, debaixo da qual acha-se o açougue, e à direita acima d'ella a prisão, e uma grande parte da cidade, sendo a eminencia em cima plana e egual; tambem alli existe uma bella e larga rua ultimamente chamada Rua Nova, que foi a primeira rua da cidade. Porem, no extremo meridional, onde está situado o hospital, chamado Misericordia, desce o monte com tão aspero declive, que quasi não pode-se subil-o sem grande esforço (...) Chegando-se em baixo no valle, onde acha-se uma encruzilhada na qual os mercadores se reunem e costumam constituir a bolsa, sobe-se logo de novo outra eminencia, mas, não tão alta, e alli encontra-se a outra egreja parochial chamada egreja de São Pedro, e alli em volta acham-se muitas bellas casas e muitos armazens, porque este é o extremo da praça, onde o rio vindo do Recife chega e corre pela parte occidental. As casas não são baldas de conforto, mas, commodas e bem feitas, arejadas por grandes janellas, que estão ao nível do sotão ou celleiro, mas sem vidros (...) (Baers, 1898, p.39.)

O cronista holandês J. Baers, integrante das tropas invasoras sob o comando do coronel Diederick van Waerdenburch, relacionou os aspectos topográficos do sítio e a localização dos edifícios principais próprios à ocupação colonial portuguesa. Pontuou, igualmente, a existência de distintas aglomerações e a fonte de água para beber que, naquele momento, era um dos mais importantes elementos urbanos. Essa descrição referenda as palavras de Diogo de Campo Moreno:

As casas esparcidas e as ruas de modo desencaminhadas que uma de per si faz um bairro, e as igrejas distantes e desacompanhadas. (Mello, 1995, p.146.)

Campos Moreno fala de um crescimento desigual da vila de Olinda, indicando a dispersão das edificações. Já as palavras de Baers enunciam imagens de uma maior dinâmica urbana, ao indicar pontos de encontro (igreja e bolsa) e de abastecimento, além de arrabaldes, ou seja, Baers descreve a existência de usos e funçōes urbanas distintos. Da leitura do seu texto, depreende-se a permanência, ao longo de um século (1537-1630), do plano de ocupação territorial formulado por Duarte Coelho.

A beleza da vila de Olinda, a concepção de ocupação territorial de Duarte Coelho contida no Foral, a composição urbana realizada a partir da torre de pedra e cal, a localização estratégica das edificações religiosas, a dependência urbanística entre a vila e o porto dos Arrecifes dos Navios, foram de imediato apropriadas pelos holandeses, pelo olhar de Baers, que minuciosamente traduziu os elementos urbanos a serem destruídos e esquecidos. A rememoração desses fatos põe tais vivências no presente como memórias a permanecerem no futuro. 


\section{PRÁTICAS URBANÍSTICAS: VERSÕES SOBRE MEMÓRIA E ESQUECIMENTO}

O incêndio de Olinda foi tratado pelo historiador Cabral de Mello (1986) como um fato constante da história da restauração pernambucana. Em sua obra, esse historiador examina os elos entre a ocupação holandesa e as representações mentais dos portugueses e brasileiros, desde o período flamengo até os últimos decênios do século XIX. Estão mostradas as relações sociais subjacentes às modificações sofridas pelo sentimento nativista em Pernambuco, relativos à nobreza da terra, aos mascates e à população livre do século XIX.

Ao desvelar a visão nativista sobre o tempo dos holandeses e especialmente a quem caberia a responsabilidade pela conquista de Pernambuco, Cabral de Mello (1986, p.242) constrói duas leituras: a providencialista e a político-militar. A primeira reporta-se à explicação da invasão holandesa como castigo divino pelos pecados dos moradores de Pernambuco. Essa leitura foi elaborada com base nos relatos de memorialistas luso-brasileiros, entre os quais o de Calado (1985). A segunda refere-se às injunçôes políticas entre o poder de mando e de unificação da coroa e às rivalidades locais dos proprietários de terras com os comerciantes:

A condenação moral dos cronistas luso-brasileiros havia recaído sobre o conjunto da população da capitania; após a restauração, ela adquirira uma conotação desfavorável à nobreza da terra e aos mazombos. Fernando Gama lhe imprimirá um sentido antiluzitano, utilizando o topos da corrupção dos citadinos e da pureza dos rústicos, que podia ser comodamente enxertada na distinção entre comerciantes reinóis e senhores de engenho mazombos, vale dizer, na dicotomia herdada da segunda metade do século XVII e começos do século XVIII. (Cabral de Mello, 1986, p.272.)

Ao tratar das diversas visões dos cronistas sobre quem caberia a responsabilidade pela invasão holandesa, mostra esse historiador que elas extravasam ora um sentimento antilusitano, ora um acolhimento e enaltecimento pelos luso-brasileiros.

A narrativa empreendida por Cabral de Mello é diversa da esboçada neste texto. Essas idéias versam, naquela narrativa, acerca dos fatos sociais da restauração pernambucana, e nesta, sobre a configuração urbanística efetivada pelos luso-brasileiros em Olinda. Outra diferença é quanto ao registro da narrativa, isto é, o incêndio de Olinda não está tematizado por Cabral de Mello como um ato de esquecimento, mas ele interpreta as representaçôes culturais que os luso-brasileiros elaboraram a partir da ocupação holandesa. Portanto, o registro e percurso adotados são diversos, não existindo vinculação direta entre as argumentações, embora se esteja tratando de um mesmo fato: o incêndio de Olinda e as mentalidades culturais. Entretanto, cabe pontuar, como convergência entre as narrativas, o ato de rememoração, a recorrência ao passado para estabelecer os limites de uma discussão posta no presente.

Pode-se dizer, a partir da interpretação empreendida neste texto, que o incêndio de Olinda foi desejado pelos holandeses como um modo de esquecer os vestígios de uma outra experiência - a lusitana. Entretanto, tal assertiva é apenas uma parte da questão posta. A outra é estabelecer um paralelo entre esse ato de esquecimento, em um passado remoto, e as atuais práticas urbanísticas de requalificação efetivadas em sítios históricos. 
$\mathrm{Na}$ atualidade, o discurso dos urbanistas alega que as transformaçōes econômicas, sociais e culturais requerem adaptações desses sítios. Não fazê-las seria sustar a dinâmica da história desses sítios e levá-los à completa estagnação e ruína. No âmbito desse consenso, verificam-se as mais diversas práticas urbanísticas, variando desde aquelas mais apegadas aos vestígios do passado às mais flexíveis, ligadas aos fluxos da economia e aos modismos consumistas.

O que preservar e como preservar um sítio histórico não é uma polêmica nova e restrita à cidade de Olinda. As primeiras medidas de preservação aparecem no século XV nas bulas papais, porém é no século XIX, com a Revolução Industrial, que elas adquirem uma forma mais permanente e sistematizada. Para tanto, constituem contribuiçóes fundantes as idéias de John Ruskin, na Inglaterra, e de Viollet-le-Duc, na França. No século passado, ou mais precisamente, em 1964, é subscrita por urbanistas de várias partes do mundo a Carta de Veneza, propagando a noção de valor de antigüidade e contrapondo-se aos preceitos do urbanismo moderno, principalmente os estabelecidos na Carta de Atenas, em 1933. Após a Carta de Veneza, sucedem-se outros encontros internacionais que firmaram conceitos e metodologias específicas à prática urbanística em sítios históricos. Entre os encontros realizados, cabe destacar o de Amsterdã (1975), por fixar o conceito de conservação integrada como uma estratégia de planejamento direcionada não apenas às áreas históricas mas a todo o território da cidade, e o de Lisboa (1995), por nominar e definir modos de intervenção em sítios históricos.

No Brasil, o Decreto-Lei no 25, de 1937, estabelece o instituto do tombamento, sendo este o primeiro instrumento legal de proteção ao patrimônio arquitetônico de interesse histórico. Paralelamente também é criado o Serviço do Patrimônio Histórico Nacional (Sphan), com a atribuição de fazer a guarda desse patrimônio. Desde então, políticas e instrumentos jurídicos e urbanísticos têm sido estabelecidos, ampliados e adotados, igualmente, nos âmbitos estaduais e municipais, seguindo em parte as discussões internacionais.

Para os mais aferrados às idéias preservacionistas, a experiência de Bolonha, proposta no Piano di Intervento Operativo e di Restauro per L'Edilizia Economica e Popolare, nos anos de 1960, constitui-se num paradigma a ser seguido (Cervallati e Scannavini, 1976). Essa experiência corresponderia, segundo Arantes (2000), aos projetos de primeira geração de urbanistas voltados para o trato da cidade e dos conjuntos históricos.

A premissa desse Plano era de articular a reabilitação física de áreas históricas degradadas com a de natureza social, de modo a promover a recuperação socioeconômica da área e dos seus moradores. Entretanto, para muitos tal paradigma foi superado pelos de Baltimore, Londres e Barcelona, nos anos de 1970 e 1980, relativos à segunda geração de projetos de renovação. Nestes últimos, a premissa preponderante é a da rentabilidade financeira, instrumentalizada pelo planejamento estratégico, cujo jargão técnico central, como diz Hall (1995, p.420), é "explorar oportunidades".

Assim, semelhantes práticas urbanísticas estratégicas estão, em parte, dirigidas pelos novos arranjos e exigências da economia internacional, por meio de uma " união simbiótica entre rentiers, planejadores urbanos e intermediários culturais na construção de consensos cívicos" (Arantes, 2000, p.29), e em parte, estão alicerçadas na teoria da conservação urbana, segundo a Declaração de Amsterdã (1975). Se até a promulgação dessa declaração os princípios e normas urbanísticos relativos à proteção patrimonial diziam respeito apenas aos sítios históricos, a partir de então passam a visar ao conjunto de lugares da cidade. Assim, ocorreu uma flexibilização e ampliação das práticas de proteção da arquitetura e do tecido urbano antigo. 
O Sítio Histórico de Olinda é um exemplo das distintas práticas urbanísticas de preservação dos sítios históricos. Os primeiros germens dessas experiências podem ser encontrados em 1967, com a visita a Olinda do consultor da Unesco, Michel Parent, que propõe uma estratégia de proteção que articule base legal, econômica e urbanística. Esse consultor recomenda o tombamento da colina histórica, a montagem de uma infraestrutura básica para captação de fluxos turísticos e, finalmente, a elaboração de um plano urbanístico que assegure a preservação da colina histórica.

O Plano Diretor Local Integrado de Olinda, elaborado em 1973, segue as diretrizes e recomendações encaminhadas por Parent: estabelecer o zoneamento do Sítio Histórico de Olinda e uma estratégia de valorização a ser promovida mediante ação do poder público, tendo como base "o reaparelhamento e/ou ampliação dos equipamentos sociais situados no setor, a implantação de órgãos públicos, ou privados, de função cultural ou de interesse turístico, preferentemente em monumentos integrantes do conjunto" (Prefeitura Municipal de Olinda, Lei n. ${ }^{\text {o } 3823 / 1973, ~ a r t i g o ~ 97) . ~}$

Um contraponto à perspectiva turística e uma identificação com os projetos da primeira geração foi posta, em 1984, com o Projeto Piloto de Olinda. Esse projeto, considerado um modelo para as demais experiências de preservação dos sítios históricos brasileiros, tinha como proposta:

A busca conjunta de fórmulas de intervenção que possibilitem o tratamento dos núcleos históricos preservando suas características ambientais e culturais, melhorando as condições da população residente, recuperando não só o patrimônio habitacional e ambiental como os equipamentos comunitários e a infra-estrutura urbana. (Prefeitura Municipal de Olinda, 1984.)

Importa referir que data dessa época o surgimento da Sociedade de Defesa da Cidade Alta de Olinda, que terá relevante papel na defesa da memória e dos valores culturais da cidade, colocando-se na contramão dos interesses turísticos. Tal perspectiva urbanística será esgotada nos anos 1990, quando as práticas urbanísticas assumem o discurso e as diretrizes do planejamento estratégico.

Pode-se dizer que o Plano Diretor de Olinda, de 1997, é uma versão local do planejamento estratégico, no qual se evidenciam o acento demasiadamente ufanístico próprio das premissas desse planejamento e a afirmação, como oportunidade e potencialidade econômica, do turismo cultural, em razão, principalmente, de seu sítio histórico:

O foco deve ser dirigido ao aproveitamento do Sítio Histórico através da criação de uma estrutura turística adaptada às condições locais (...) Nesse sentido pode-se estimular o surgimento de pousadas e a oferta de alojamentos em residências da Cidade Alta, a construção de infra-estrutura de informações turísticas, a definição de roteiros culturais, eventos artísticos e culturais, etc. que venham dinamizar o aproveitamento econômico dessa potencialidade até aqui pouco explorada. (Prefeitura Municipal de Olinda, 1997.)

Essa diretriz econômica foi o mote principal dos planos de revitalização urbana de Baltimore e Boston, apelidados por Hall (1995, p.412-5) de "rousificação", em referência ao empresário James Rouse, principal protagonista dessa modalidade de prática urbanística. Outra vertente dessa prática provém das idéias de Jordi Borja (1996; 1996a), cuja influência no Brasil tem sido significativa, devido à sua participação em eventos técnicos e em planos e projetos a convite de prefeituras municipais. ${ }^{7}$ Além de ter transposto
7 A exemplo do Projeto Capital da cidade do Recife e do Programa Santo André Cidade Futuro, ambos a convite das municipalidades e iniciados em 1997. 
8 A Carta de Lisboa define como reabilitação: "É uma estratégia de gestão urbana que procura requalificar a cidade existente através de intervenções múltiplas destinadas a valorizar as potencialidades sociais, econômicas e funcionais (...)"; revitalização: "engloba operações destinadas a relancar a vida econômica e social de uma parte da cidade em decadência. Esta noção, próxima da reabilitação urbana, aplica-se a todas as zonas da cidade sem ou com identidade e características marcadas"; requalificação: "aplica-se a locais funcionais diferentes da 'habitação'; trata-se de operacões destinadas a tornar a dar uma atividade adaptada a esse local e no contexto atual"; renovação: "ação que implica a demolição das estruturas morfológicas e tipológicas existentes numa área degrada e a sua consequente substituição por um novo padrão urbano (...) Hoje estas estratégias desenvolvem-se sobre tecidos urbanos degradados aos quais não se reconhecem valor como patrimônio arquitetônico ou conjunto urbano a preservar".

9 A Secretaria de Planejamento Urbano, Obras e Meio Ambiente da Prefeitura Municipal de Olinda elaborou a primeira versão do Programa de Reabilitação do Patrimônio Cultural Urbano - perfil de projetos - roteiro para informações básicas, em março de 1997. As negociações com o Banco Interamericano de Desenvolvimento (BID) exigiram que fossem realizados os ajustes e as complementações, tendo sido produzidas mais duas versões, uma ainda em 1997 e outra em 1999, quando a proposta foi então aprovada. Em abril de 2000, foi assinado o convênio entre o BID, governos federal, estadual e municipal, iniciando-se a sua execução. essa prática, o Plano Diretor de Olinda, de 1997, referendou as idéias contidas na Carta de Lisboa, de 1995, resultado do $1^{\circ}$ Encontro Luso-Brasileiro de Reabilitação Urbana de Centros Históricos. Esse encontro de urbanistas preservacionistas, preocupados com as intervenções em curso em sítios históricos, procurou conceituar intervenções de modo a não serem superadas pelas práticas emergentes, daí ter-lhes conferido o cunho de "estratégias".

Assim, foi transcrito nesse plano diretor, ao explicitar as proposiçōes de âmbito físico, os conceitos de reabilitação, revitalização, requalificação e renovação urbanas, ${ }^{8}$ sendo atribuído às divisóes territoriais da cidade essas nomeclaturas. Seria possível, num passe de mágica que elas tivessem força de se fazer valer e compensar um outro ideário, cujos efeitos parecem não garantir a memória e a identidade de um lugar? $\mathrm{O}$ que se quer mostrar é a ambigüidade das práticas urbanísticas ao tratar de um lugar cuja memória tem importância histórica, mas que elas se revestem de ações que redundam também num apagar de vestígios.

A proposta mais recentes de turistificação do sítio histórico de Olinda também está presente no Programa de Reabilitação ou Programa Monumenta/BID, ${ }^{9}$ elaborado em meados da década de 1990, no qual se deu prioridade aos investimentos que propiciassem a instalação de novas empresas e negócios ligados ao setor terciário, fossem elas de pequeno ou grande porte. Esse programa, segundo Rodrigues (2000, p.4), embora dele tenham sido implantadas apenas as pequenas ações, já pode ser avaliado pelos seus impactos no sítio histórico. $\mathrm{O}$ incentivo à criação de associações de pequenos negócios teve imediata acolhida, como a da Associação da Rua do Amparo, em 1998. O estudo realizado por Rodrigues aponta, entre suas consequiências, o acréscimo da quantidade de veículos em circulação, principalmente de carga, vindo a comprometer a capacidade de carga dos seus morros e intensificando as rachaduras nos monumentos, e "a elevação das descaracterizações na volumetria e na tipologia das edificações, em acréscimo de área construída com a ocupação de quintais e na destruição da vegetação", ameaçando a paisagem desse sítio histórico. Após inventariar e analisar as transformaçóes, Rodrigues escreveu as seguintes palavras:

Concluímos que o fator mudança de uso e a adequação necessária para atender o programa exigido por ele, vem descaracterizando os imóveis do sítio histórico de Olinda (...) Conclui-se que todos os imóveis, componentes da Associação da Rua do Amparo, passaram por descaracterização (...) Após essas alterações, as informações vão sendo perdidas ao longo do tempo. $\mathrm{O}$ que poderia ser considerado como um processo histórico de adequação e evolução do uso do espaço (...) é simplesmente destruído. (Rodrigues, 2000, p.112-3 e 9.)

As eloqüentes palavras de uma jovem arquiteta, ao constatar fatos, mostram quão ambíguas são as práticas urbanísticas, nas quais discurso e gesto se mesclam, compondo uma sinfonia desafinada e diluindo a memória do lugar.

Neste sentido, Jeudy (1990), referindo-se a experiências de intervenção em outros sítios históricos, mostra que as novas práticas urbanísticas têm conduzido à redução das diferenças e à uniformização das culturas, ou seja, opera-se a diluição da memória e da identidade do lugar. A cidade, de objeto histórico, torna-se "estética da memória". Esse esvanecimento da memória de um lugar seria um modo de esquecimento, de apagamento dos vestígios de um outro tempo. Não há como negar que a menor alteração na arquitetura de uma cidade significa apagar a vivência passada, significa perda. 
Se as afirmaçôes de Jeudy falam das distorções provocadas por práticas urbanísticas pouco cuidadosas para com a memória do lugar, o filósofo pernambucano Evaldo Coutinho, no filme documentário ${ }^{10}$ A composiçãso do vazio, mostra que, ao se adentrar, por exemplo, uma igreja gótica está-se vivenciando espaços arquiteturais relativos a outros hábitos culturais, está-se voltando no tempo. Desse modo, a arquitetura da cidade proporciona imbricação temporal, vivências múltiplas. Essas vivências situam-se como uma razão de ser construída pelo homem. Esse entendimento converge para o de Benjamim (1985), ao considerar que os vestígios perdidos seriam uma maneira de justaposição temporal do viver na cidade, permanecendo apenas semelhanças.

As práticas urbanísticas recentes levadas ao sítio histórico de Olinda inserem-se no âmbito dessa polêmica. Sejam planos diretores, sejam programas de renovação urbana, as intervençôes desenhadas e efetivadas nesse sítio têm introduzido modificações que esvanecem a memória do lugar. Mas, indo ao encontro de Benjamim (1985), ao recuperar a arquitetura das cidades quinhentistas e seiscentistas, adaptando-as às exigências da atualidade, segue-se o princípio da semelhança. Traz-se o passado para o presente, retifica-se o ontem no amanhã. Esse pensar retificador constitui uma rememoração. Tomando emprestadas palavras de Antônio Augusto Arantes (1984, p.14) para dispensar maiores elucubrações, afirma-se uma perspectiva subjetiva: "Lugares e objetos são evocados como sinais topográficos e vasos recipientes da história da sensibilidade e da formação das emoções."

Portanto, as práticas urbanísticas efetivadas em sítios históricos, mesmo aquelas que aplicam os princípios da conservação urbana, inscrevem-se na ambigüidade de atos de memorização e de esquecimento.

\section{REFERÊNCIAS BIBLIOGRÁFICAS}

ARANTES, O. B. F. Urbanismo em fim de linha e outros estudos sobre o colapso da modernização arquitetônica. São Paulo: Edusp, 1998.

. Uma estratégia fatal: a cultura nas novas geraçōes urbanas. In: ARANTES, O.; VAINER, C.; MARICATO, E. A cidade do pensamento único: desmanchando consensos. Petrópolis: Vozes, 2000.

ARANTES, A. A. (Org.). Produzindo o passado: estratégias de construção do patrimônio cultural. São Paulo: Brasiliense/Secretaria de Estado da Cultura/SEC-Condephaat, 1984.

BAERS, J. Olinda conquistada. Recife: Typographia de Laemmut \& C. Editores, 1898.

BARLAEUS, G. História dos feitos recentemente praticados durante oito anos no Brasil. Recife: Prefeitura da Cidade do Recife/Secretaria de Educação e Cultura/Fundação de Cultura Cidade do Recife, 1980.

BENJAMIN, W. Magia e técnica, arte e política: ensaios sobre literatura e história da cultura. São Paulo: Brasiliense, 1985.

BERNARDES, D. Para reler o Recife e suas origens. In: REZENDE, A. P. (Org.). Recife: que história é essa?. Recife: Fundação de Cultura da Cidade do Recife, 1987.

BORJA, J.; FORN, M. de. Políticas da Europa e dos Estados para as cidades. In: Revista Espaço \& Debates. São Paulo: Núcleo de Estudos Regionais e Urbanos, ano XVI, n.39, 1996.

BORJA, J.; Castells, M. As cidades como atores políticos. In: Revista Novos Estudos Cebrap - Dossiê Cidades, n.45, julho de 1996a.
10 Esse filme documentário mostra a vida e obra do filósofo Evaldo Coutinho, tendo sido produzido por Marcos Enrique Lopes e lançado na cidade do Recife em março de 2001.

Virgínia Pontual, arquiteta, é professora do Programa de Pós-Graduação em Desenvolvimento Urbano da Universidade Federal de Pernambuco. E-mail: vp@elogica.com.br

Vera Milet, arquiteta, é professora do Centro de Conservação Integrada Urbana e Territorial da Universidade Federal de Pernambuco. E-mail:

altodase@hotlink.com.br 
O L I N D A, M E M Ó R I A E E S Q U E C I M E

BRANDÃO, A. F. Diálogos das grandezas do Brasil. 3.ed. Recife: Fundaj/Editora Massangana, 1997.

CALADO, Frei M. O Valeroso Lucideno e triunfo da liberdade. 4.ed. Recife: Fundarpe, 1985.

CASTELLO, L. Imparare da Serafina: a trama das percepçóes estimuladas. In: Anais... 2001, Rio de Janeiro. IX ENCONTRO NACIONAL DA ASSOCIAÇÃO NACIONAL DE PÓS-GRADUAÇÃO E PESQUISA EM PLANEJAMENTO URBANO E REGIONAL. Rio de Janeiro: Anpur. 2001.

CERVAlLATI, P. L.; SCANNAVINI, R. Bolonia, Política y Metodologia de la Restauración de Centros Históricos. Barcelona: Gustavo Gilli, 1976.

CARTA DE LISBOA. Carta de reabilitação urbana integrada. Outubro de 1995.

DECLARAÇÃO DE AMSTERDÃ. Conselho da Europa. Outubro de 1975. In: CURY, I. (Org.). Cartas Patrimoniais. 2.ed. ver.aum. Rio de Janeiro: Instituto do Patrimônio Histórico e Artístico Nacional (Iphan), 2000.

HALL, P. Cidades do amanhã. São Paulo: Editora Perspectiva, 1995.

HARVEY, D. A condição pós-moderna: uma pesquisa sobre as origens da mudança cultural. São Paulo: Edições Loyola, 1993.

Do gerenciamento ao empresariamento: a transformação da administração urbana no capitalismo tardio. In: Revista Espaço \& Debates. São Paulo: Núcleo de Estudos Regionais e Urbanos, ano XVI, n.39, 1996.

JEUDY, H.-P. Memórias do social. Rio de Janeiro: Forense Universitária, 1990.

LE GOFF, J. História e memória. Campinas: Editora da Unicamp, 1996.

LAET, J. de. Historia ou Annaes dos Feitos da Companhia Privilegiada das Indias Occidentaes. Rio de Janeiro: Officinas Graphicas da Biblioteca Nacional, 1916.

MELLO, E. C. de. Rubro veio: o imaginário da restauração pernambucana. Rio de Janeiro: Nova Fronteira, 1986.

. A fronda dos Mazombos: nobres contra mascates; Pernambuco, 1666-1715. São Paulo: Companhia das Letras, 1995

MELLO, J. A. G. de. Tempo dos flamengos: influência da ocupação holandesa na vida e na cultura do Norte do Brasil. 3.ed. Recife: Fundaj/Editora Massangana, 1987.

Homenagem a Olinda Patrimônio Cultural da Humanidade. In: Grandes Moinhos do Brasil S/A Indústrias Gerais, Relatório 82/83. Recife, 1983.

. O chamado Foral de Olinda, de 1537. In: Revista do Arquivo Público. Recife: Arquivo Público Estadual - Governo do Estado, ano XI, n.13, dez./1974.

MENEZES, J. L. M. Olinda: evolução urbana. In: CARITA, H.; ARAUJO, R. (Coord.) Coleção de estudos universo urbanistico português - 1415-1822. Lisboa: Comissão Nacional para as Comemoraçóes dos Descobrimentos Portugueses, 1998. . Olinda e Recife - 1537/1630. Recife: s.n., s.n. (Mimeo.)

OLIVEIRA, B. S. de. Espaço e estratégia: considerações sobre a arquitetura dos jesuítas no Brasil. Uberlândia: Prefeitura Municipal de Uberlândia, 1988.

OLIVEIRA, V. M. A. de. Projeto Foral de Olinda. Relatório Final. Olinda: Prefeitura Municipal de Olinda, 1996.

ORAMAS, L. P. Frans Post, invenção e "aura" da paisagem. In: HERKENHOFF, P. (Org.). O Brasil e os holandeses (1630-1654). Rio de Janeiro: Sextante Artes, 1999.

PREFEITURA MUNICIPAL DE OLINDA. Plano Diretor de Olinda. Olinda: PMO/Secretaria de Planejamento Urbano, Obras e Meio Ambiente, 1997. (Versão preliminar.) . Programa de Reabilitação do Patrimônio Cultural Urbano - perfil de projetos 
- roteiro para informações básicas. Recife: PMO/Iphan/MINC/BID, mar./1997. (1a versão)

. Projeto Piloto Olinda. Olinda: Fundação Centro de Preservação dos Sítios Históricos de Olinda, 1984.

PREFEITURA MUNICIPAL DE OLINDA. Plano Diretor Local Integrado do Municipio de Olinda. Olinda: PMO/Sociplan/Serfhau, 1973. v.I, II e III.

. Legislação Básica Urbanística, Lei n.o 3.823/73. In: Plano Diretor Local Integrado do Municipio de Olinda. Olinda: PMO/Sociplan/Serfhau, 1973. v.IV.

REIS FILHO, N. G. Contribuição ao estudo da evolução urbana do Brasil - 1500/1720. São Paulo: Livraria Pioneira Editora/Editora da Universidade de São Paulo, 1968.

RODRIGUES, C. R. Monitoramento das transformaçôes nas tipologias arquitetônicas e nos indices urbanisticos do sitio histórico de Olinda. (Trabalho graduação), 2000. Recife: Departamento de Arquitetura e Urbanismo/UFPE.

SALVADOR, Frei V. do. História do Brasil: 1500-1627. São Paulo, 1975.

SOUZA, G. S. de. Tratado descriptivo do Brasil em 1587. 3.ed. São Paulo: Companhia Editora Nacional, 1938.

VICENTINI, I. Teorias da cidade: reformas urbanas contemporâneas. In: IX ENCONTRO NACIONAL DA ASSOCIAÇÃO NACIONAL DE PÓS-GRADUAÇÃO E PESQUISA EM PLANEJAMENTO URBANO E REGIONAL. Anpur. Rio de Janeiro, 2001. Anais... Rio de Janeiro, Anpur/Ippur/UFRJ, 2001.

A B S T R A C T This article discusses recent urban practices in historical sites. It highlights those practices which have been praised by some professionals for being a new and efficient way of thinking about towns and cities and criticised by others for being "cultural marketeering". Another argument put forward is that some practices consider the history of a place as a cultural value but weaken its uniqueness and singularity through intervention. The article explores the reconstitution of the historical formation of the site of Olinda by answering the following question: which urban planning practices lead to the weakening or the strengthening of the historical preservation of a place? Thus, facts of the past are cited that seem to indicate why the result was destruction and loss. Throughout the article the discussion is related to the descriptions of annalists and texts of historians who report the formation of the then small town in the Captaincy of Pernambuco.

K E Y W O R D S History; urban planning; practices; urban formation; memory; forgetfulness. 